\title{
The Mathematical Basis of the Calendar Used by the Ethiopian Orthodox Twahedo Church for Fasting Periods and Religious Holidays
}

\author{
Simegne Tafesse \\ Department of Mathematics, Haramaya University, P O Box 88, Ethiopia \\ E-mail: Simegnetafesse@yahoo.ca
}

\begin{abstract}
The Ethiopian Orthodox Twahedo Church (EOTC) has been the most dominant religion fully supported by the government for many years. EOTC has its own calendar, which is genuinely respected by the people. Nowadays, the Ethiopian people officially celebrate five major religious holidays every year: the New Year called 'Inqutatash', Holy Cross, Christmas, Epiphany and Easter. Easter has no fixed date. The dates of some of the fasting periods and the religious holidays also vary from year to year. In this paper, number theory is applied to the determination of the calendar for the fasting periods and major holidays of the EOTC whose dates vary from year to year.
\end{abstract}

Keywords: Division Algorithm; 'Nenewe' Fasting Period; New Year 'Inqutatash'; Number Theory; Theory of Congruence

\section{Introduction}

The Ethiopian Orthodox Twahedo Church (EOTC) has its own calendar which is used to determine the fasting periods and holidays of the church (http://www.ethiopic.com/calendar/ethiopic.htm). The Church has many fasting periods and holidays, the dates of which are determined annually. Some of these dates vary from year to year and they are announced at the ceremony New Year in the Church. Only some of the priests can perform the computation of the variable dates of holidays and fasting periods using the church calendar. Almost all of the followers of the church do not know how to compute the variable dates of the holidays and fasting periods of their religion.

There are two types of fasting periods and holidays, these are:

i) Fasting periods and holidays whose dates vary from year to year. For instance, the 'Nenewe' fasting period and Easter.

ii) Fasting periods and holidays whose dates are fixed. For instance Christmas and the 'Filseta' fasting period.

There is no problem regarding the fasting periods and holidays whose dates are fixed, since the Church followers know them very well.

This paper considers the fasting periods and holidays whose dates vary from year to year. The writer investigates how the dates of these fasting periods and holidays in a given year are arrived at and tries to show how the modern mathematical concept of congruence can be applied to determine of the dates of fasting periods and holidays.

The EOTC has its own calendar. It is the sum of the number 5500 and a year in today's Ethiopian calendar. The EOTC assumes the number 5500 as the era between the creation of Adam and the birth of Jesus Christ (Meseret, 1988). It is referred to as 'Amete Alem'.

The Amete Alem of a year $y$ in E.C. is $5500+y$. For instance, the Amete Alem of 1999 in E.C. is $5500+$ $1999=7499$.
Ethiopia uses its own calendar and we call it the Ethiopian Calendar. The Ethiopian Calendar is based on the church's calendar. It is fairly similar to the Ethiopian Orthodox Twahedo Church calendar except that the number 5,500 has to be subtracted from the church's calendar. It has 13 months. The first 12 months have 30 days each. The last month, known as Pagumen, has 5 days and every fourth year, called leap year, it has 6 days (Simegne, 2002).

\section{Materials and Methods}

The author used different books from the Church to analyze and incorporate with the new mathematical concepts in to the Ethiopian calendar. He also carried out interviews with some priests who know how to compute the dates of these holidays and fasting periods to collect information.

\subsection{The EOTC Aiwadat (Cycles)}

The following constant numbers except the number 4 according to the church are called 'Aiwadat'. The constant numbers 4, 19, 28, 76, and 532 indicate a group of years which is used to compute the fasting periods and the holidays whose dates vary from year to year. They are described briefly (Meseret, 1988; Asrat and Gebrehiwot, 1995) as follows.

1. 7 is referred to as 'Awde Ilet'. It is the length of week cycle in which a day of a week is repeated.

2. 30 is referred to as 'Awde Werha'. It is the length of a month cycle in which a number given to a day of a month is repeated except the $13^{\text {th }}$ month called 'Pagumen' according to the church solar year.

3. 365.25 is referred to as 'Awde Amet'. It is the length of a solar year.

4. 4 is the length of the four year cycle in which the Evangelical name of a year is repeated.

5.19 is referred to as 'Awde Abktie'. It is the length of a cycle in which the phase of a moon is repeated (Metonic cycle). It is also known as 'Nius Kemer' in the EOT church. 
6. 28 is referred to as 'Awde Tsehay'. It is the length of the cycle in which the concurrence of the day and the evangelical name of a year is repeated. This can be justified mathematically as 28 is the least common multiple of 4 and 7 . In the Julian Calendar this cycle is called the Solar Cycle.

7. 76 is referred to as 'Awde Mahtem'. It is the length of the cycle in which the concurrence of Abektie and the evangelical name of a year is repeated. This can be justified mathematically as 76 is the least common multiple of 4 and 19. It is also called 'Maikelawi Kemer' in the church.

8. 532 is referred to as 'Awde Kemer'. This is the length of a cycle in which concurrence of the day, evangelical name and 'Abktie' of a year is repeated. This can be justified mathematically as 532 is the least common multiple of 7, 4 and 19 .

\subsection{Terminology}

There are many Terminological terms used in EOTC, Some of, which are very important in the study, and are defined as follows.

'Nenewe' Fasting Period the 'Nenewe' fasting Period is one of the fasting periods whose dates vary from year to year. It is a three-day fasting period. It is also the key for the other fasting periods and religious holidays whose dates vary from year to year. If you know the first date of the 'Nenewe' fasting period, then the dates for other fasting periods and holidays can be easily calculated from a simple mathematical computation. Therefore, the main problem is determining the first date of the 'Nenewe' fasting period.

In the past, people did not follow formal procedures with regard to respecting fasting periods and holidays.

Pope Dimetros, in about 200-224 A.C, introduced special mathematical formulations and announced axioms for the dates of the first days of the fasting periods and holidays whose dates varied from year to year.

The Ethiopian Orthodox Twahedo Church adopted these axioms and mathematical formulations and has been using them ever since. The church announces these dates for its followers every year at the New Year ceremony 'Inqutatash'.

'Wenber' is assumed as a remainder of an era (Meseret, 1988; Asrat and Gebrehiwot, 1995). It is the basis for the Abektie and Metik, which will be defined later. It has a Mathematical definition which is formulated by Pop Dimetros.

'Abektie' is a remainder of a certain mathematical calculation depending on the 'Wenber' value (Meseret, 1988; Asrat and Gebrehiwot, 1995). It has a constant coefficient which is provided by Pop Dimetros. This constant coefficient is 11 .

'Metik' is again a remainder depending on the numerical value of 'Wenber' (Meseret, 1988; Asrat and Gebrehiwot, 1995). Just like Abektie, Metik has a constant coefficient assigned by Pop Dimetros. Its constant coefficient is 19 . 'Metik' is used to determine the first dates of fasting periods and holidays whose dates are variable.
The day of 'Metik' itself is, in fact, a holiday and it either in the month of 'Meskerem' (September) or 'Tikimt' (October). Its value is a date of a month.

'Tewusak' is a constant number that is used to fulfill the requirement of the regulation formulated by Pope Dimetros (Meseret, 1988; Asrat and Gebrehiwot, 1995). Weekdays and each holiday whose dates are variable have their own 'Tewusak'.

Table 1. Weekdays 'Tewusak'.

\begin{tabular}{lll}
\cline { 2 - 3 } N.O. & Day & Tewusak \\
\hline 1. & Saturday & 8 \\
2. & Sunday & 7 \\
3. & Monday & 6 \\
4. & Tuesday & 5 \\
5. & Wednesday & 4 \\
6. & Thursday & 3 \\
7. & Friday & 2 \\
\hline
\end{tabular}

'Mebaja Hamer' is a date number of a day, which is defined as the sum of 'Metik' and the 'Metik' day 'Tewusak' (Meseret, 1988; Asrat and Gebrehiwot, 1995). It either in the month of 'Meskerem' or 'Tikmt' depending on the day of 'Metik'. The value of 'Mebaja Hamer' is the date of the 'Nenewe' first fasting day after four full months or 120 days of its dates.

\section{Results and Discussions}

\subsection{Mathematical Framework}

Before coming to the definition given by the Church and theorems we are concerned with, let us examine some points of division algorithms and the theory of congruence.

For any positive integer $m$ the relation $R_{m}=\{(a, b): a \equiv$ $\mathrm{b}(\bmod \mathrm{m}), \mathrm{a}$ and $\mathrm{b}$ are integers $\}$ is an equivalence relation on $Z$. The equivalence classes can be given by

$\{\overline{0}, \overline{1}, \overline{2}, \ldots, \overline{m-1}\}$, where for

$r \in\{0,1,2, \ldots, m-1\}, \bar{r}=\{r+m x: x \in Z\}$.

For any integer a, by the division algorithm, $a=m q+r$ with unique integers $q, r$ and $0 \leq r<m$. Hence, $a \in \bar{r}$ for some $r \in\{0,1,2, \ldots, m-1\}$.

Definition 1: A subset $\mathrm{S}$ of the set of integers is called a complete system of residue modulo $\mathrm{m}$ iff for any integer $\mathrm{b}$ there exists $\mathrm{r} \in \mathrm{S}$ such that $\mathrm{b} \equiv \mathrm{r}(\bmod \mathrm{m})$ and any two elements of $\mathrm{S}$ are incongruent modulo $\mathrm{m}$.

The set $\{0,1,2, \ldots, m-1\}$ is a complete system of residues modulo $\mathrm{m}$ and it is the least complete residue class representatives modulo $\mathrm{m}$.

Theorem 1: Suppose $a+c \equiv b(\bmod m) \quad$ and $c \equiv d(\bmod m)$. Then $b=d$ iff $a \equiv 0(\bmod m)$.

Theorem 2: If $a \equiv b(\bmod m)$ and $c \equiv d(\bmod m)$, then $a+c \equiv(b+d)(\bmod m) \quad$ and $\quad a c \equiv b d(\bmod m)$ (Uspensky, 1939; Oystein, 1948 and Yismaw, 1995). 


\subsection{Evangelist's Name of a Year in E.C.}

There are four Evangelists, who wrote the Holy Gospel. These are Johannes (John), Mathewos (Mathew), Markos (Mark) and Lukas (Luke). Every year in the Ethiopian Calendar is associated with the name of the Evangelist's (Kidanemariam, 1963). The following statement defines the relationship of Evangelists name and the church calendar 'Amete Alem' to a year with the help of congruence theory.

Definition 2: Let y be a year in the Ethiopian Calendar such that

Then

$$
5500+\mathrm{y} \equiv \mathrm{R}_{0}(\bmod 4), \text { where } 0 \leq \mathrm{R}_{0}<4
$$

i) If $\mathrm{R}_{0}=0$, then the year is called 'Zemene' John.

ii) If $R_{0}=1$, then the year is called 'Zemene' Mathew.

iii) If $\mathrm{R}_{0}=2$, then the year is called 'Zemene' Mark.

iv) If $\mathrm{R}_{0}=3$, then the year is called 'Zemene' Luke.

Theorem 3 states the idea of definition 2 with respect to the Ethiopian Calendar only and the proof follows.

Theorem 3: Let y be a year in the E.C.

If $5500+\mathrm{y} \equiv \mathrm{R}_{0}(\bmod 4)$, where $0 \leq \mathrm{R}_{0}<4$ and $\mathrm{y} \equiv \mathrm{R}_{0}^{\prime}(\bmod 4)$, where $0 \leq \mathrm{R}_{0}^{\prime}<4$, then

$$
\mathrm{R}_{0}=\mathrm{R}_{0}^{\prime} \text {. }
$$

Proof: It follows from the fact that $5500 \equiv 0(\bmod 4)$. We will use $\mathrm{R}_{0}$ for the determination of 'Inqutatash'.

\section{3. 'Inqutatash'}

The first day of the Ethiopian New Year is known as 'Inquatash'. This is the day on which the dates of the holidays and fasting periods for the coming year are announced. Here we shall provide the mathematical definition of 'Inqutatash' for an arbitrary year in E.C. (Simegne, 2004).

Rabiet: From definition 2 we have $5500+\mathrm{y} \equiv \mathrm{R}_{0}(\bmod$ 4) where $y$ is a year in E.C. Then by the definition of congruence

$5500+\mathrm{y}-\mathrm{R}_{0}=4 \mathrm{I}_{\mathrm{r}}$, for some integer $\mathrm{I}_{\mathrm{r}}$

$\Rightarrow I_{r}=\frac{5500+y-R_{0}}{4}$

The integer $\mathrm{I}_{\mathrm{r}}$ is known as 'Rabiet'.

Definition 3: Let y be a year in the Ethiopian Calendar such that

$5500+\mathrm{y}+\mathrm{I}_{\mathrm{r}} \equiv \mathrm{R}_{1}(\bmod 7)$, where $1 \leq \mathrm{R}_{1} \leq 7$

Then 'Inquatash' is the $\mathrm{R}_{1}{ }^{\text {th }}$ day starting from Tuesday. According to the Church, the day Tuesday is known as

'Tinte kemer' (Kidanemariam, 1963; Asrat, 1991).

The next theorem states definition 3 with respect to the Ethiopian Calendar only and the proof follows.

Theorem 4: Let y be a year in the E.C. If $\mathrm{R}_{0}$ is as in Definition 2 and

$5 \mathrm{y}-\mathrm{R}_{0} \equiv \mathrm{R}_{1}^{\prime}(\bmod 28)$, where $0 \leq \mathrm{R}_{1}^{\prime}<28$,
2. $\mathrm{R}_{1}=1+\frac{R_{1}^{\prime}}{4}$, where $\mathrm{R}_{1}$ is the non negative integer as given in equation (3).

Proof: 1 . Suppose $5 \mathrm{y}-\mathrm{R}_{0} \equiv \mathrm{R}_{1}(\bmod 28)$, where $\mathrm{y}$ is a year in E.C. and $R_{0}$ is as in the Definition 2. Then

$28 \mid 5 \mathrm{y}-\mathrm{R}_{0}-\mathrm{R}_{1}^{\prime}$ and then $5 \mathrm{y}-\mathrm{R}_{0}-\mathrm{R}_{1}^{\prime}=28 \mathrm{I}$, for some integer I.

Then $\quad \mathrm{R}_{1}^{\prime}=5 \mathrm{y}-\mathrm{R}_{0}-28 \mathrm{I}$

$$
\begin{aligned}
& =4 \mathrm{y}+\mathrm{y}-\mathrm{R}_{0}-28 \mathrm{I} \\
& =4 \mathrm{y}+4 \mathrm{I}^{\prime}-28 \mathrm{I}, \quad \text { for some integer } \mathrm{I}^{\prime} .
\end{aligned}
$$

Since by theorem $1 \mathrm{y} \equiv \mathrm{R}_{0}(\bmod 4)$

$$
\begin{aligned}
& =4\left(\mathrm{y}+\mathrm{I}^{\prime}-7 \mathrm{I}\right) \\
& =4 \mathrm{n} \text {, where } \mathrm{n}=\mathrm{y}+\mathrm{I}^{\prime}-7 \mathrm{I}
\end{aligned}
$$

Therefore, $\mathrm{R}_{1}^{\prime} \equiv 0(\bmod 4)$.

Moreover, since $R_{1}^{\prime} \in[0,28)$ and $R_{1}^{\prime}$ is an integer, the possible values of $\mathrm{R}_{1}^{\prime}$ are $0,4,8,12,16,20,24$. Thus $\frac{R^{\prime}}{4}$ can only be one of the numbers $0,1,2,3,4,5,6$.

2. Suppose $5 \mathrm{y}-\mathrm{R}_{0} \equiv \mathrm{R}_{1}^{\prime}(\bmod 28)$, where $\mathrm{y}$ is a year in E.C. and $\mathrm{R}_{0}$ is the number corresponding to Evangelist's name. Then $5 \mathrm{y}-\mathrm{R}_{0}-\mathrm{R}_{1}^{\prime}=28 \mathrm{I}^{\prime}$, for some integer I'. Then

$\frac{5 y-R_{0}}{28}=I^{\prime}+\frac{R_{1}^{\prime}}{28}$ for some $I^{\prime} \in \mathrm{Z}, 0 \leq R_{1}^{\prime}<28$ and

$\mathrm{R}_{1}^{\prime}$ is an integer.

By Definition 2 we know that

i) By (1) we have $\mathrm{R}_{1}^{\prime} \equiv 0(\bmod 4) \Rightarrow \mathrm{R}_{1}^{\prime}=4 \mathrm{k}_{1}$

ii)By Theorem 2 we have $\mathrm{y} \equiv \mathrm{R}_{0}(\bmod 4) . \Rightarrow \mathrm{y}-\mathrm{R}_{0}=4 \mathrm{k}_{2}$

Since $5 \mathrm{y}-\mathrm{R}_{0} \equiv \mathrm{R}^{\prime}{ }_{1}(\bmod 28)$

$\Rightarrow 4 \mathrm{y}+\mathrm{y}-\mathrm{R}_{0} \equiv \mathrm{R}^{\prime}{ }_{1}(\bmod 28)$

$\Rightarrow 4 \mathrm{y}+4 \mathrm{k}_{2} \equiv 4 \mathrm{k}_{1}(\bmod 28)$

$\Rightarrow \mathrm{y}+\mathrm{k}_{2} \equiv \mathrm{k}_{1}(\bmod 7)$

But $6875 \equiv 1(\bmod 7)$

From (5) and (6) we have

$6875+\mathrm{y}+\mathrm{k}_{2} \equiv\left(1+\mathrm{k}_{1}\right)(\bmod 7)$

Again since $5500+\mathrm{y}+\mathrm{I}_{\mathrm{r}} \equiv \mathrm{R}_{1}(\bmod 7)$ by definition 3

where $I_{r}=\frac{5500+y-R_{0}}{4}$

$$
\begin{aligned}
& =\frac{5500+4 k_{2}}{4} \\
& =1375+\mathrm{k}_{2}
\end{aligned}
$$

It gives $5500+\mathrm{y}+1375+\mathrm{k}_{2} \equiv \mathrm{R}_{1}(\bmod 7)$

$$
6,875+\mathrm{y}+\mathrm{k}_{2} \equiv \mathrm{R}_{1}(\bmod 7)
$$

From (7) and (8) we have $1+\mathrm{k}_{1}=\mathrm{R}_{1}$

Since $\mathrm{k}_{1}=\frac{R_{1}^{\prime}}{4}$ we have $\mathrm{R}_{1}=1+\frac{R_{1}^{\prime}}{4}$. This completes the proof.

Let us consider the following example:

To find the day of 'Inqutatash' of the year 2000 in E.C. using the above method, we proceed as follows.

First, let us find the number of the Evangelist's name for the year. 
Suppose $2000 \equiv \mathrm{R}_{0}^{\prime}(\bmod 4)$, where $0 \leq \mathrm{R}_{0}^{\prime}<4$. Now we find $R_{0}, \frac{2000}{4}=500+\frac{0}{4}$, then $R_{0}=0$ which is 'Zemene' John.

Inqutatash: $5 y-\mathrm{R}_{0} \equiv \mathrm{R}_{1}^{\prime}(\bmod 28)$, where $0 \leq \mathrm{R}_{1}^{\prime}<28$

28 Since $\mathrm{R}_{0}$ is 0 .

$$
\Rightarrow 5(2000)-0 \equiv \mathrm{R}_{1}^{\prime}(\bmod 28), \text { where } 0 \leq \mathrm{R}_{1}^{\prime}<
$$

$\Rightarrow 10000-R_{1}=28 \mathrm{k}$ for some $\mathrm{k} \in \mathrm{Z}$

$$
\frac{10,000}{28}=k+\frac{R^{\prime} 1}{28}=357+\frac{4}{28} .
$$

Thus $\mathrm{R}_{1}^{\prime}=4$ and $\mathrm{k}=357$

Therefore, $\mathrm{R}_{1}=1+\frac{\mathrm{R}_{1}^{\prime}}{4}=1+\frac{4}{4}=1+1=2$. Therefore 'Inqutatash' of 2000 E. C. is on Wednesday.

\section{4. 'Tewusak' of Fasting Periods and Holidays Whose Dates Vary From Year to Year}

This is a number which can be defined as the residue of the number of days counted from the starting day of the 'Nenewe' fasting period up to holiday itself or the first date of the fasting period modulo 30 . That is, let $\mathrm{H}$ be the holiday and $\mathrm{k}$ be the number of days from the starting day of the 'Nenewe' fasting period. Suppose $k \equiv \mathrm{R}_{6}(\bmod$ 30). Then the 'Tewusak' of $H$ is $R_{6}$.

The 'Nenewe' fasting period has no 'Tewusak'.

\section{5. 'Wenber'}

The next definition is the computation used by the church with respect to 'Amete Alem' in a year with the help of congruence theory (Asrat, 1991).

Definition 4: Let y be a year in E.C such that $5500+\mathrm{y} \equiv \mathrm{R}_{2}(\bmod 532)$, where $1 \leq \mathrm{R}_{2} \leq 532$

and then $\mathrm{R}_{2} \equiv \mathrm{R}_{3}(\bmod 19)$, where $1 \leq \mathrm{R}_{3} \leq 19$

Then 'Wenber' is defined as $R_{3}-1$.

Theorem 5 states definition 4 with respect to the Ethiopian Calendar only and the proof follows.

Theorem 5: Let y be a year in E.C. such that $\mathrm{y} \equiv \mathrm{R}_{3}{ }^{\prime}(\bmod 19)$, where $1 \leq \mathrm{R}_{3}{ }_{3} \leq 19$

Then

1. $\mathrm{R}_{3}= \begin{cases}R_{3}^{\prime}+9, & \text { if } 1 \leq R_{3}^{\prime} \leq 10 \\ R_{3}^{\prime}-10, & \text { if } 11 \leq R_{3}^{\prime} \leq 19\end{cases}$

2. 'Wenber' $=\mathrm{R}_{3}-1=$

$$
\left\{\begin{array}{l}
R_{3}^{\prime}+8, \quad \text { if } 1 \leq R_{3}^{\prime} \leq 10 \\
R_{3}^{\prime}-11, \quad \text { if } 11 \leq R_{3}^{\prime} \leq 19
\end{array}\right.
$$

Proof: 1. Let $y$ be a year in E.C. Suppose $y \equiv \mathrm{R}_{3}{ }^{\prime}(\mathrm{mod}$ 19), where $1 \leq R_{3}^{\prime} \leq 19$. Then, by the hypothesis of Definition 4, we have

$5500+\mathrm{y} \equiv \mathrm{R}_{2}(\bmod 532)$ where $1 \leq \mathrm{R}_{2} \leq 532$ then

$5500+\mathrm{y}-\mathrm{R}_{2}=532 \mathrm{k}$ for some $\mathrm{k} \in \mathrm{Z}$

$\Rightarrow \mathrm{R}_{2}=5500+\mathrm{y}-532 \mathrm{k}$
$\mathrm{R}_{2} \equiv \mathrm{R}_{3}(\bmod 19)$ where $1 \leq \mathrm{R}_{3} \leq 19$ then $\mathrm{R}_{2}-\mathrm{R}_{3}=19 \mathrm{n}$ for some $\mathrm{n} \in \mathrm{Z}$

$\Rightarrow \mathrm{R}_{2}=\mathrm{R}_{3}+19 \mathrm{n}$

Putting (14) in (15) we have

$5500+\mathrm{y}-532 \mathrm{k}=\mathrm{R}_{3}+19 \mathrm{n}$

$\Rightarrow 5500+\mathrm{y}-532 \mathrm{k} \equiv \mathrm{R}_{3}(\bmod 19)$

But $532 \equiv 0(\bmod 19)$ then $532 \mathrm{k} \equiv 0(\bmod 19)$ for some $\mathrm{k}$ $\in$ Z

Thus $5500+\mathrm{y} \equiv \mathrm{R}_{3}(\bmod 19)$

Again $5500 \equiv 9(\bmod 19)$ and by the hypothesis of the theorem

$\mathrm{y}=\mathrm{R}_{3}(\bmod 19)$

Thus $5500+\mathrm{y} \equiv\left(9+\mathrm{R}_{3}^{\prime}\right)(\bmod 19)$.

This is by Theorem 2 .

If $9+\mathrm{R}_{3}^{\prime}>19$ which means $\mathrm{R}_{3}^{\prime}>10$, then we can take $5500+\mathrm{y} \equiv\left(\mathrm{R}_{3}^{\prime}-10\right)(\bmod 19)$.

Since the integer $\mathrm{R}_{3}$ is between 1 and 19 inclusively from (16), (17) and (18) we have

$\mathrm{R}_{3}=\left\{\begin{array}{l}R_{3}^{\prime}+9, \quad \text { if } 1 \leq R_{3}^{\prime} \leq 10 \\ R_{3}^{\prime}-10, \quad \text { if } 11 \leq R_{3}^{\prime} \leq 19\end{array}\right.$

2. From 1. and Definition 3 it follows that 'Wenber' $=\mathrm{R}_{3}-1=$

$$
\left\{\begin{array}{l}
R_{3}^{\prime}+8, \quad \text { if } 1 \leq R_{3}^{\prime} \leq 10 \\
R_{3}^{\prime}-11, \quad \text { if } 11 \leq R_{3}^{\prime} \leq 19
\end{array}\right.
$$

The proof is completed.//

Based on the value of 'Wenber' for a year, 'Abektie' and 'Metik' will be defined as follows.

\subsection{1. 'Abektie'}

Definition 4: If $11 \mathrm{w} \equiv \mathrm{R}_{4}(\bmod 30)$,

where $\mathrm{R}_{4} \in \mathrm{Z}, 0 \leq \mathrm{R}_{4} \leq 30$ and $\mathrm{w}=$ 'Wenber', then $\mathrm{R}_{4}$ $=$ 'Abektie'

Note that 'Wenber' has only 19 different values from 1 to 19 inclusive. Since 'Abektie' is a function of 'Wenber', the number of values of 'Abektie' are limited to only 19 different values. These are $0,1,3,4,6,7,9,11,12,14,15$, $17,18,20,22,23,25,26,28$. For one year in the E.C., there is only one 'Abektie' value. The constant coefficient of 'Abektie' is 11 .

\subsection{2. 'Metik'}

It is the basis for the determination of the starting day of the 'Nenewe' fasting period. Like 'Abektie', 'Metik' is a function of 'Wenber' and has only 19 different values. The mathematical definition of 'Metik' is given as follows.

Definition 5: If $19 \mathrm{w} \equiv \mathrm{R}_{5}(\bmod 30)$

where $\mathrm{w}=$ 'wenber' and $0<\mathrm{R}_{5} \leq 30$, then $\mathrm{R}_{5}=$ 'Metik'

If $R_{5}=0$ then we take $R_{5}=30$ and then 'Metik' becomes 30.

The number 19 is the constant coefficient of 'Metik'. Just like 'Abektie', The 19 values of 'Metik' are 2, 4, 5, 7, 8, 9, $10,12,13,15,16,18,19,21,23,24,26,27,29,30$. For one year in the E.C., there is only one 'Metik' value. 
Note: Suppose $R_{5}$ is in as in equation (20). As we mentioned above, 'Metik' is assumed to be a holiday in the church and its day is dated by $\mathrm{R}_{5}$ either in the month of 'Meskerem' or 'Tikemt' in the E.C. If $\mathrm{R}_{5}>14$, then the day of 'Metik' is held on the $\mathrm{R}^{\mathrm{th}_{5}}$ of 'Meskerm'. If $\mathrm{R}_{5}<14$, then the day of 'Metik' is held on $\mathrm{R}^{\mathrm{th}_{5}}$ of 'Tikimt'. Theorem 6: Let 'Abektie' $=\mathrm{R}_{4}$ and 'Metik' $=\mathrm{R}_{5}$, then

$R_{4}+R_{5}=30$

Proof: Let w be 'Wenber'. By the definition

$19 \mathrm{w} \equiv \mathrm{R}_{4}(\bmod 30)$

$11 \mathrm{w} \equiv \mathrm{R}_{5}(\bmod 30)$

Then by the Theorem 3 we have

$(11+19) \mathrm{w} \equiv\left(\mathrm{R}_{4}+\mathrm{R}_{5}\right)(\bmod 30)$

$\Rightarrow 30 \mathrm{w} \equiv\left(\mathrm{R}_{4}+\mathrm{R}_{5}\right)(\bmod 30) \quad$ But $30 \mathrm{w} \equiv 0(\bmod 30)$

$\Rightarrow \mathrm{R}_{4}+\mathrm{R}_{5} \equiv 0(\bmod 30) \Rightarrow \mathrm{R}_{4}+\mathrm{R}_{5}$ is a multiple of 30 .

Since $0<\mathrm{R}_{4} \leq 30$ and $0 \leq \mathrm{R}_{5}<30$ we have $0<\mathrm{R}_{4}+\mathrm{R}_{5}<$ 60. Since 30 is the only integer which is a multiple of 30 between 0 and 60 exclusively, then we can conclude that $\mathrm{R}_{4}+\mathrm{R}_{5}=30$.

The proof is complete.

\section{6. 'Mebaja Hamer'}

This is also another term which depends on the value of 'Metik' .

Definition 6: 'Mebaja Hamer' is defined as the sum of 'Metik' and the 'Tewusak' of the day. That means.

'Mebaja Hamer' = 'Metik' + 'Tewusak' of the day.

The day of 'Mebaja Hamer' is administered on:

i) The date of its value in the month of 'Meskerem' in E.C., if $14<\mathrm{R}_{5} \leq 30$

ii) The date of its value in the month of 'Tikimt' in E.C., if $\mathrm{R}_{5}<14$

\section{7. 'Nenewe' Fasting Period}

As we mentioned before, 'Nenewe' fasting is a three-day fasting period. It always starts on Monday and ends on Thursday of the same week. It is a function of 'Mebaja Hamer'. We know that the value 'Mebaja Hamer' is the date of a day either in the month of 'Meskerem' or 'Tikmt'.

The starting day of the 'Nenewe' fasting period in a year is the day of a month exactly four full months (120 days) after the day of 'Mebaja Hamer' in the year in the E.C. That means the date of the starting day of the 'Nenewe' fasting period is exactly the value of 'Mebaja Hamer' but 'Nenewe' takes place after four months of 'Mebaja Hamer'.

Note: If 'Mebaja Hamer' is in 'Meskerem', the 'Nenewe' fasting period will be in Tir and begin on the day dated at the 'Mebaja Hamer' value. If 'Mebaja Hamer' is in 'Tikimt', then it will be in 'Yekatit' and begin on the day dated at the 'Mebaja Hamer' value (Kidanemariam, 1963; Asrat, 1991).

'Theorem 7: The 'Nenewe' fasting period cannot be administered before 'Tir' 17 and after 'Yekatit' 21.

Proof: The proof is simple.
4.8. Other Fasting Periods and Holidays Whose Dates Vary From Year to Year

Once the 'Nenewe' fasting period for a given year is determined, the other fasting periods and holidays can easily be obtained with the help of their 'Tewusak' as defined before.

Table 2. describes the 'Tewusak' $\mathrm{R}_{6}$ of fasting periods and holidays whose dates vary from year to year.

\subsection{Procedures}

The procedures of computing the days of the fasting periods and holidays of any year in E. C. whose dates vary from year to year, are given as follows.

i) Find the number $R_{0}$ that corresponds to the Evangelical name of the year.

ii) Find the day of 'Inqutatash' (Ethiopian New Year)

iii) Find the first date of the 'Nenewe' fasting period. To obtain this we need to calculate the values of 'Wenber', 'Metik' and 'Mebaja Hamer'

iv) Find all the other fasting periods and holidays with the help of their 'Tewusaks'.

Let us see some particular cases:

1. To find all the fasting days and Holidays in 1996in the E.C. whose dates vary from year to year, using the above method we proceed as follows.

i) Evangelical Name: Since $y \equiv R_{0}^{\prime}(\bmod 4)$, where $0 \leq R_{0}^{\prime}$ $<4$, y is a year, then we have $1996 \equiv \mathrm{R}_{0}^{\prime}(\bmod 4)$ where 0 $\leq \mathrm{R}_{0}^{\prime}<4$. That is $1996-\mathrm{R}_{0}^{\prime}=4 \mathrm{k}$ for some integer $\mathrm{k}$.

$$
\Rightarrow 1996 \div 4=499+\frac{0}{4} \text {, This implies that }
$$

$\mathrm{R}_{\mathrm{o}}=\mathrm{R}_{0}^{\prime}=0$.

Therefore, the Evangelical name for 1996 E.C. is 'Zemene' John.

ii) 'Inqutatash': $5 \mathrm{y}-\mathrm{R}_{0} \equiv \mathrm{R}_{1}(\bmod 28)$, where $0 \leq \mathrm{R}_{1}<28$

$$
5 \times 1996-\mathrm{R}_{0} \equiv \mathrm{R}_{1}^{\prime}(\bmod 28)
$$

$\Rightarrow$ Since $\mathrm{R}_{0}=0$ then we have $\quad 9980-\mathrm{R}_{1}=28 \mathrm{k}$ for some integer $\mathrm{k}$

$$
\begin{aligned}
& \Rightarrow \frac{9980}{28}=356+\frac{12}{28} \\
& \Rightarrow \mathrm{R}^{\prime}{ }_{1}=12 .
\end{aligned}
$$

Thus $\mathrm{R}_{1}=\frac{R_{1}}{4}+1=\frac{12}{4}+1=4$

Therefore, four days after Tuesday is Friday. Thus 'Inquatash' was held on Friday.

iii) The 'Nenewe' Fasting Period :

'Wenber': $\mathrm{y} \equiv \mathrm{R}_{3}{ }^{\prime}(\bmod 19)$, 
where $1 \leq \mathrm{R}_{3}^{\prime} \leq 19 \Rightarrow 1996 \equiv \mathrm{R}_{3}{ }^{\prime}(\bmod 19)$ $\Rightarrow \frac{1996}{19}=105+\frac{1}{19} \Rightarrow R_{3}{ }^{\prime}=1$ and it is between 1 and 10 .

Then $\mathrm{R}_{3}=\mathrm{R}_{3}{ }^{\prime}+9=1+9=10$ Therefore, 'Wenber' is $10-1=9$

'Metik':_19w $\equiv \mathrm{R}_{5}(\bmod 30) \Rightarrow 19 \mathrm{x} 9 \equiv \mathrm{R}_{5}(\bmod 30)$

$\Rightarrow \frac{171}{30}=5+\frac{21}{30} \Rightarrow 171 \equiv 21(\bmod 30)$. Therefore,

'Metik' $=\mathrm{R}_{5}=21$.

Table 2. Other fasting periods and holidays.
Interpretation: Since $21>14$, the holiday of 'Metik' will be held on $21^{\text {st }}$ of 'Meskerem' and the day is Thursday.

'Mebaja Hamer': The 'Tewusak' of Thursday is 3. Thus 'Mebaja Hamer' is $21+3=24$

The 'Nenewe' Fasting period began on 'Tir' 24, 1996 after four full months of 'Meskerem' 24.

iv) Now all the other fasting and holidays whose dates vary from year to year can be computed easily with the help of their 'Tewusak'.

\begin{tabular}{|c|c|c|c|}
\hline No & $1^{\text {st }}$ day of fasting / day of holiday & $\begin{array}{l}\text { No of days from first day } \\
\text { of 'Nenewe' fasting period }\end{array}$ & $\mathrm{R}_{6}$ \\
\hline 1. & Main fasting period (8 weeks fasting) & 14 & 14 \\
\hline 2. & 'Debrezeit' ( half of the main fasting period) & 41 & 11 \\
\hline 3. & 'Hosaina' (Historical events of Jesus palm Sunday) & 62 & 2 \\
\hline 4. & Thursday praise & 66 & 6 \\
\hline 5. & 'Siklet' (crucifixion) & 67 & 7 \\
\hline 6. & Easter & 69 & 9 \\
\hline 7. & The $2^{\text {nd }}$ Easter (day of Thomas) & 76 & 16 \\
\hline 8. & 'Rikbe kahinat' ( day of Priests ) & 93 & 3 \\
\hline 9. & 'Irget' (Ascension) & 108 & 18 \\
\hline 10. & 'Paraklitos' & 118 & 28 \\
\hline 11. & Preachers fasting period (Apostles' fasting) This is up to 'Hamle' 6 & 119 & 29 \\
\hline 12. & Friday Wednesday fasting begins & 121 & 1 \\
\hline
\end{tabular}

2. To find the first day of 'Nenewe' fasting period 1999 E.C. we proceed as follows.

i) Evangelical Name: Since $y \equiv \mathrm{R}_{0}^{\prime}(\bmod 4)$, where $0 \leq \mathrm{R}_{0}^{\prime}$ $<4$ y is a year, then we have $1999 \equiv \mathrm{R}_{0}^{\prime}(\bmod 4)$ where 0 $\leq \mathrm{R}_{0}^{\prime}<4$. That is $1999-\mathrm{R}_{0}^{\prime}=4 \mathrm{k}$ for some integer $\mathrm{k}$. $\Rightarrow \mathrm{R}_{\mathrm{o}}=\mathrm{R}_{0}{ }^{\prime}=3$. Therefore, the Evangelical name for 1996 E.C. is 'Zemene' Luk.

ii) 'Inquatash': $5 \mathrm{y}-\mathrm{R}_{0} \equiv \mathrm{R}_{1}{ }_{1}(\bmod 28)$, where $0 \leq \mathrm{R}_{1}{ }_{1}<28$ $\Rightarrow 5 \times 1999-R_{0} \equiv R_{1}^{\prime}(\bmod 28) \quad \Rightarrow$ Since $R_{0}=3$ then we have

$9995-3 \equiv \mathrm{R}_{1}^{\prime}(\bmod 28) \Rightarrow 9992-\mathrm{R}_{1}=28 \mathrm{k}$ for some integer $\mathrm{k}$

$\Rightarrow \mathrm{R}_{1}^{\prime}=24$ Thus $\mathrm{R}_{1}=\frac{R_{1}^{\prime}}{4}+1=\frac{24}{4}+1=7$. Therefore, we count 7 days from Tuesday. Then the day is Monday. That is, 'Inqutatash' will be held on Monday.

iii) 'Nenewe' Fasting Period :

'Wenber': $\mathrm{y} \equiv \mathrm{R}_{3}{ }^{\prime}(\bmod 19)$, where $1 \leq \mathrm{R}^{\prime}{ }_{3} \leq 19 \Rightarrow 1999 \equiv$ $\mathrm{R}_{3}{ }^{\prime}(\bmod 19) \Rightarrow R_{3}{ }^{\prime}=4$ and it is between 1 and 10 .
Then $\mathrm{R}_{3}=\mathrm{R}_{3}^{\prime}+9=4+9=13$ Therefore, 'Wenber' is $13-1=12$

'Metik':_19w $\equiv \mathrm{R}_{5}(\bmod 30) \Rightarrow 19 \times 12 \equiv \mathrm{R}_{5}(\bmod 30)$

$\Rightarrow 228 \equiv \mathrm{R}_{5}(\bmod 30) \Rightarrow 228 \equiv 18(\bmod 30)$. Therefore, 'Metik' $=\mathrm{R}_{5}=18$.

Interpretation: Since $18>14$ the holiday of 'Metik' will be held on $18^{\text {th }}$ of 'Meskerem' and the day is Thursday.

'Mebaja Hamer': The 'Tewusak' of Thursday is 3. Thus 'Mebaja Hamer' is $8+3=21$

The 'Nenewe' fasting period will begin on 'Tir' 21, 1999 after four full months of 'Meskerem' 21.

\section{Acknowledgement}

I would like to acknowledge Dr. Yismaw Alemu, Department of Mathematics, Addis Ababa University who encouraged and advised me from the very beginning of the paper. I would like also to acknowledge Dr. Rao, G.S. and Ms. Emilie Pamplona, Department of Mathematics Haramaya University for reading the paper and giving me fruitful suggestions, last but not least I thank Dr. Sisay Menkir, Haramaya University, for his encouragement. 


\section{References}

Abera, M. The Ethiopian Calendar (http://www.ethiopic.com/calendar/ethiopic.htm) (Accessed on April 4, 2006)

Asrat, G. M. 1991. 'Timbrte Melekot' (in Amaharic language), Ethiopia. pp.295-320.

Asrat, G. M. and GebreHiwot, M. 1995. 'Zemene aqotater' (in Amaharic language). Addis Ababa, Ethiopia.

Uspensky, J.V., and Heaslet, M.A. 1939. Elementary Number Theory. McGRAW-HILL Book Company, Inc., New York and London

Kidanemariam, G. 1963. Mashashal Yetelemede Hig New' (in Amaharic language); Primary level first book. Tinsae Z Gubae printing; Addis Ababa, Ethiopia.

Kidanemariam, G. 1963. 'Mashashal Yetelemede Hig New' (in Amaharic language); Secondary level second book. Tinsae Z Gubae printing; Addis Ababa, Ethiopia.
Kidanemariam, G. 1963. 'Mashashal Yetelemede Hig New' (in Amaharic language); Tertiary level third book. Tinsae Z Gubae printing; Addis Ababa, Ethiopia.

Meseret, S. 1988. 'Tiwfitawi Hassabe Zemenina Tariku'(in Amaharic language). New Life Literature Ltd., Hong Kong.

Oystein, O. 1948. Number Theory and its History. McGRAW-HILL Book Company, Inc., New York, Toronto and London. pp. 209-225.

Simegne, T. 2004. Mathematical formulation on the "Inkutatash day (Ethiopian New Year) of any year in the Ethiopian Calendar. Alemaya University Critical Practitioner Inquiry News letter Vol.1 No 2. Alemaya, Ethiopia.

Simegne, T. 2002. Gregorian Calendar Versus Ethiopia Calendar. Alemaya University News Letter Vol.2 No 3. Alemaya, Ethiopia.

Yismaw, A. 1995. Introduction to Elementary Theory of Number. Addis Abeba University, Ethiopia. pp.46-73. 